\title{
Violencia, censura y medios de comunicación en Colombia: Ios efectos del Bogotazo y el colapso en las transmisiones radiales
}

\author{
Roger Pita Pico** \\ Recibido: 2017-11-05. Enviado a pares: 2017-11-10. \\ Aprobado por pares: 2018-01-12. Aceptado: 2018-01-20 \\ https://doi.org/10.22395/angr.v17n33a7
}

\begin{abstract}
Resumen
La historiografía colombiana se ha centrado principalmente en el estudio de la violencia desde la perspectiva del conflicto armado pero sin abordar a profundidad el impacto en otros sectores de la sociedad, como es el caso de las telecomunicaciones. Es por esto que, a través del método de análisis cualitativo de fuentes documentales, testimoniales, impresas y secundarias, el objetivo de este artículo consiste en examinar la compleja relación entre violencia y medios de comunicación en Colombia a través de un estudio de caso: el papel de la radio tras los hechos violentos ocurridos en el Bogotazo, el 9 de abril de 1948.

Así entonces, se intenta demostrar, por un lado, los alcances insospechados de la radio en coyunturas especiales de violencia en las que, además de ser una canal habitual de información, se transformó en un espacio para despertar apasionados sentimientos, desde arengas y llamados a la lucha política, hasta intentos por aplacar y persuadir a las multitudes. Por el otro, se observa cómo un hecho político violento generó un colapso y un caos en las transmisiones radiales a escala nacional que dieron lugar a una fuerte censura e intervención estatal, lo cual a su vez significó un punto de inflexión que abrió paso a una serie de cambios profundos en el funcionamiento, en las tendencias y en los contenidos de este medio de comunicación en la segunda mitad del siglo XX.
\end{abstract}

Palabras clave: radio, medios de comunicación, política, violencia, Colombia, siglo XX.

Artículo de investigación. Trabajo derivado del proyecto de investigación titulado Telecomunicaciones y orden público en Colombia: una cuestión de seguridad nacional, 1860-1960 que adelanta el autor con el apoyo institucional de la Academia Colombiana de Historia. Grupo de investigación sobre nuevas miradas a la historia de la violencia en Colombia.

* Politólogo de la Universidad de los Andes (Bogotá), especialista en Política Social y magíster en Estudios Políticos de la Pontificia Universidad Javeriana. Director de la Biblioteca Eduardo Santos de la Academia Colombiana de Historia. rogpitc@hotmail.com Orcid: https://orcid.org/0000-0001-9937-0228 


\title{
Violence, censorship and media in Colombia: effects of the "Bogotazo" and the collapse in radio broadcasts
}

\begin{abstract}
Colombian historiography has focused mainly on the study of violence from the perspective of the armed conflict but without addressing in depth the impact on other sectors of society, such as telecommunications. That is why, through the method of qualitative analysis of documentary, testimonial, printed and secondary sources, the goal of this paper is to examine the complex relationship between violence and media in Colombia through a case study: The role of the radio after the violent events that occurred in the "Bogotazo" on April 9, 1948.

Thus, it is intended to show, on the one hand, the unsuspected reaches of the radio in special conjunctures of violence in which, in addition to being a habitual channel of information, it was transformed into a space to awaken passionate feelings: from harangues and calls to the political struggle, even attempts to placate and persuade the crowds. On the other, it is observed how a violent political event caused a collapse and chaos in the radio broadcasts on a national scale that led to a strong censorship and state intervention, which in turn meant a turning point that opened the way to a series of profound changes in the functioning, trends and content of this media in the second half of the twentieth century.
\end{abstract}

Keywords: radio, media, politics, violence, Colombia, 20th century.

\section{Violência, censura e meios de comunicação na Colômbia: os efeitos do Bogotazo e o colapso nas transmissões radiais}

\begin{abstract}
Resumo
A historiografia colombiana centrou-se principalmente no estudo da violência a partir da perspectiva do conflito armado, mas sem abordar com profundidade o impacto em outros setores da sociedade, como é o caso das telecomunicações. É por isso que, por meio do método de análise qualitativa de fontes documentais, de depoimentos, impressas e secundárias, o objetivo deste artigo consiste em examinar a complexa relação entre violência e meios de comunicação na Colômbia por meio de um estudo de caso: o papel da rádio depois dos fatos violentos ocorridos no Bogotazo, no dia 9 de abril de 1948.

Desse modo, tentamos demonstrar, por um lado, os alcances insuspeitos da rádio em conjunturas especiais de violência nas quais, além de ser um canal regular de informação, transformou-se num espaço para despertar apaixonados sentimentos, de discursos e chamadas para a luta política, até tentativas de acalmar e persuadir as multidões. Por outro lado, observa-se como um fato político violento gerou um colapso e um caos nas transmissões radiais à escala nacional que deram lugar a uma forte censura e intervenção estatal, o qual, por sua vez, significou um ponto de inflexão que abriu caminho para uma série de mudanças profundas no funcionamento, nas tendências e nos conteúdos desse meio de comunicação na segunda metade do século XX.
\end{abstract}

Palavras-chave: rádio, meios de comunicação, política, violência, Colômbia, século XX. 


\section{Introducción}

Los primeros experimentos radiales tuvieron lugar a principios del siglo XX en Estados Unidos, Francia y Argentina. Rápidamente el mundo se percató de sus usos y alcances, tanto en épocas de paz como en tiempos de guerra interna y externa ${ }^{1}$.

En el siglo XIX, al poco tiempo de haber alcanzado su independencia de España, Colombia se sumergió en un espiral de violencia casi constante. Primero, padeció una ola de guerras civiles atizadas por las luchas partidistas. Aunque los primeros años del siglo XX estuvieron marcados por periodos de relativa paz, la confrontación política siguió de manera intensa, particularmente entre el partido liberal y el partido conservador.

Este conflicto político adquirió dimensiones exacerbadas tras el asesinato del dirigente liberal Jorge Eliécer Gaitán ocurrido en la ciudad de Bogotá el 9 de abril de 1948 en momentos en que adelantaba su campaña a la presidencia de la República. El país se hallaba escindido políticamente y los pronósticos le conferían un inmenso favoritismo a este candidato, razón por la cual este crimen frustró las aspiraciones de sus copartidarios. Este suceso, conocido también como el Bogotazo, marcaría el inicio de la denominada época de la violencia, uno de los periodos más infaustos de la historia de Colombia.

Al momento del magnicidio, estaba al frente del poder el presidente Mariano Ospina Pérez, de filiación conservadora, situación que suscitó una álgida lucha y una persecución política que afectó también a los medios de comunicación, tanto a la prensa como a la radio.

En el marco de la reflexión que actualmente se desarrolla en el país en torno al tema del posconflicto, el propósito de este artículo consiste en analizar la compleja relación entre violencia y medios de comunicación en Colombia a través de un estudio de caso: el papel de la radio tras los hechos violentos ocurridos el 9 de abril de 1948. Así entonces, se intenta demostrar cómo un acontecimiento político violento generó un colapso y un caos en las transmisiones radiales a escala nacional que dieron lugar a una fuerte censura e intervención estatal, lo cual a su vez generó cambios profundos en el funcionamiento, en las tendencias y en los contenidos de este medio de comunicación.

Estos objetivos se analizan a partir del abordaje de las siguientes temáticas específicas: el Bogotazo y el colapso de las comunicaciones, el estallido de la radio en Bogotá, la diáspora de la "chispa" radial a escala regional, las medidas oficiales de control y las censuras fijadas en Bogotá y en las distintas regiones.

\section{Metodología}

Dentro de la interdisciplinariedad propia de las ciencias sociales, este trabajo se constituye en un espacio en el cual confluyen la historia política, la cultura política (Cárdenas, 2012) y la historia de la comunicación.

Sobre el papel de la radio en la Primera y Segunda Guerra Mundial, véase Albert y Tudesq (2002). 
La historia de la comunicación es una disciplina relativamente reciente y su desarrollo ha estado vinculado intrínsecamente al progresivo rol de importancia que han adquirido los medios de comunicación en la sociedad contemporánea ${ }^{2}$. Particularmente, los estudios sobre la violencia han ocupado un lugar central en la historiografía nacional, desde las guerras civiles hasta las nuevas violencias que han azotado a Colombia ${ }^{3}$.

La metodología para llevar a cabo esta investigación incluyó un estudio descriptivo y cualitativo a partir de la consulta e interpretación de fuentes primarias y secundarias. La mayor parte del artículo se estructuró con base en la revisión de fuentes primarias de la época, tales como: los documentos de archivo del entonces Ministerio de Correos y Telégrafos ${ }^{4}$, los periódicos, los informes oficiales y el acervo normativo.

Esta información se complementó con fuentes bibliográficas, principalmente con las recopilaciones de los testimonios de la época. Otra serie de publicaciones resultaron muy útiles para esta investigación con miras a elaborar el contexto social y político que vivía el país desde mediados del siglo XX.

\section{El Bogotazo y el colapso de las comunicaciones}

Los inicios de la radio en Colombia se remontan a la tercera década del siglo XX en los años finales de la hegemonía conservadora ${ }^{5}$. Buena parte de las primeras emisoras se concentraban en contenidos educativos y culturales aunque paulatinamente fueron permeadas por el ambiente de polarización, ante lo cual se registró un aumento de los espacios dedicados al debate y a la opinión política. La prensa escrita también se había convertido en escenario de radicalización política, lo cual se vio reflejado en el tono mordaz y a veces agresivo de los titulares, los editoriales y las caricaturas (Acevedo, 2003).

La llegada de los liberales al poder en la década del 30 le imprimió una singular dinámica a la radio, tanto en su desarrollo normativo como en la intención del Estado de utilizar este medio como espacio educativo y como medio de propaganda oficial (Gutiérrez, 2009) y, prueba de esto último, fue su uso para incitar el patriotismo y para reclutar jóvenes dispuestos a participar en la guerra con el Perú por el diferendo limítrofe en la región amazónica (Lalinde, 1998).

No fue sino hasta 1936 cuando, bajo la presidencia del dirigente liberal Alfonso López Pumarejo, se dictó la Ley 198 que es considerada la primera en el país en materia de telecomunicaciones, cuyo propósito era reglamentar la radiodifusión pública y comercial,

2 En relación con esta temática, véanse estos referentes teóricos: Checa, 2008; Schudson, 1993; Williams, 1992. Sobre el debate en torno a esta materia a escala latinoamericana, pueden revisarse los siguientes trabajos: Amaya, $2010 \mathrm{y}$ Gómez, 2015.

3 Una de las obras clásicas sobre la violencia en Colombia es el libro de Germán Guzmán, Orlando Fals Borda y Eduardo Umaña (2005).

$4 \quad$ Hoy Ministerio de las Tecnologías de la Información y las Comunicaciones.

Sobre los inicios de la radio en Colombia véanse: Téllez, 1974 y Castellanos, 2001. 
normatividad que permaneció vigente hasta 1948. Hacia 1937 surgieron los primeros experimentos de cadenas radiales con ensayos de transmisiones simultáneas en vivo.

Por estos años, las emisoras experimentaron un especial auge, particularmente aquellas de carácter comercial. En 1940 existían 74 estaciones (Cadena, 1940) y durante el gobierno conservador de Mariano Ospina Pérez se adjudicaron 13 emisoras, registrándose por estos años en el país un total de 120 (Pérez, 1998). Era una extensa red, aunque concentrada en las principales ciudades, como Bogotá, Medellín, Cali, Barranquilla y Bucaramanga, entre otras.

De todos los medios de comunicación existentes en Colombia en esta década del 40, la radio era sin duda el de mayor alcance dado que podía llegar de manera instantánea a las masasy transmitir a través de la voz toda serie de emociones ${ }^{6}$. Aun cuando también ha sido reconocido el papel de la prensa escrita como espacio de confrontación partidista, de todas formas llegaba a un reducido porcentaje de la población, por demás letrada.

Por ello, el papel de la radio en ambientes de tensión política fue, en algunos casos, decisivo. Resulta pertinente citar aquí las apreciaciones que sobre este respecto apuntó el historiador Arturo Alape:

La radio ha sido un elemento de motivación social de grande importancia en muchos de los recientes acontecimientos políticos en Colombia. Ha sido un eje conductor de la comunicación de masas; la posibilidad de llegar a los oídos más lejanos, de penetrar en lo más hondo de la geografía del país y establecer en el mismo instante de la transmisión un ambiente propicio para asumir una actitud y accionar la pasión política hasta su desbordamiento total. (1989, p. 58).

No hay que olvidar que la política se hacía y se difundía a través de la radio, en donde las divergencias se veían reflejadas en los debates y en la transmisión de acalorados discursos en una época en la cual la capacidad de oratoria llegaba a su máximo fulgor.

Las emisoras se habían convertido en un efectivo espacio de difusión durante las campañas políticas pues muchos discursos fueron transmitidos a través de estos medios logrando un gran impacto en los oyentes. El dirigente liberal Jorge Eliécer Gaitán fue precisamente uno de los que logró mayor poder de influencia, especialmente en los sectores populares de la sociedad. Muy conocidos fueron los discursos de este caudillo (Galindo, 2008) transmitidos a través de las emisoras La Voz de Bogotá y Radio Nueva Granada, las cuales, a su vez, se enlazaban con otras estaciones en distintos puntos del país (Chaves, 2014).

En esta década, dos hechos políticos de trascendencia pusieron al descubierto los insospechados alcances de la radio: el golpe de Estado en la ciudad de Pasto y el Bogotazo. El primero de estos acontecimientos ocurrió el 10 de julio de 1944 cuando el ministro de Gobierno Alberto Lleras Camargo tomó el control absoluto de las estaciones de radio en

Sobre la sociedad de masas y la psicología de las muchedumbres, véase Martín-Barbero, 2003. 
el país con el objetivo de convocar a la ciudadanía para que rechazara el golpe de Estado contra el presidente liberal Alfonso López Pumarejo (Atehortúa, 2009).

El otro episodio sucedió el 9 de abril de 1948, año en que tuvo lugar el asesinato de Gaitán. En ese momento, las emisoras se encargaron de informar abruptamente sobre el terrible acontecimiento y se convirtieron en espacios a través de los cuales los liberales y comunistas convocaron a la lucha y, al mismo tiempo, coordinaron las acciones de ataques a las instituciones y a los sectores oficialistas de orientación conservadora.

Sin lugar a dudas, este fue el día en que se registró el mayor colapso de las comunicaciones en Bogotá y en Colombia no solo en la radio sino también en la prensa escrita y en las comunicaciones telefónicas, que se vieron bastante afectadas.

Durante estos hechos violentos, se produjeron daños de consideración en varias oficinas y circuitos. Bogotá, por ser la ciudad en que tuvo lugar el crimen político, fue una de las más perjudicadas y aunque allí se concentraba la cúpula militar y policial, lo que se reflejaba en un considerable pie de fuerza, de todos modos el ímpetu masivo de la protesta terminó por imponer la violencia y el caos.

En el Palacio de Telecomunicaciones, por ejemplo, las turbas causaron destrozos en el primero y segundo piso, y en la sección jurídica, ubicada en el cuarto piso, averiaron algunos muebles y desaparecieron varios expedientes de carrera administrativa. Buena parte de las dependencias de correos fueron saqueadas, incendiadas y destruidas en su totalidad, perdiéndose poco más de un millón pesos en materiales.

Al día siguiente del asesinato, el presidente Ospina Pérez, amparado en el artículo 121 de la Constitución Nacional, declaró el estado de sitio en toda la República. Entre tanto, el Ministerio de Correos y Telégrafos, con el apoyo del Ejército y la Policía Nacional, emprendieron todos los esfuerzos conducentes a normalizar el servicio en las áreas damnificadas por la ola de violencia. Para el efecto, el ministro José Vicente Dávila Tello tramitó ante el Congreso Nacional una partida adicional para dejar en perfecto funcionamiento las comunicaciones averiadas (Ministerio de Correos y Telégrafos, 1948).

Durante estos hechos del Bogotazo quedó plenamente demostrado el poder de influencia y la capacidad de convocatoria de la radio. Una de las primeras estrategias del movimiento espontáneo de protesta surgido a raíz de este suceso histórico, conformado principalmente por liberales, comunistas y socialistas, fue tomarse las emisoras para incitar desde allí a las gentes a salir a las calles y fomentar la conformación de juntas revolucionarias en cada localidad con el fin de derrocar a las autoridades conservadoras legítimamente constituidas. Algunas de las personas que protestaban contaban con emisoras que funcionaban clandestinamente, desde donde lanzaban arengas a los liberales.

Sin embargo, cabe anotar también que muchos de los mensajes desde allí emitidos causaron más bien desconcierto e incertidumbre. De hecho, la primera noticia lanzada al aire sindicaba erróneamente a la policía "chulavita"7 del asesinato de Gaitán.

Este era el nombre con el que era conocida la policía ligada políticamente al partido conservador. 
Bajo el fervor del momento, y alimentados con el elixir del licor, no pocos se dejaron llevar por la fantasía, anunciando otras falsas noticias como la supuesta caída del gobierno conservador y la ejecución de sus más connotados directivos, también se hizo creer que las fuerzas policiales estaban totalmente doblegadas a los dictámenes de los líderes de la protesta. Así entonces, en medio de la anarquía reinante, en ciertos momentos la radio se constituyó en un medio de manipulación y confusión.

\section{El estallido de la radio en Bogotá}

Sin lugar a dudas, las emisoras de Bogotá tuvieron un especial protagonismo durante los hechos del Bogotazo por haber ocurrido allí mismo el asesinato del líder político y porque, en su condición de ciudad capital, albergaba una dinámica actividad radial.

La Radiodifusora Nacional, emisora de carácter estatal y concentrada más que todo en temas culturales, ubicada en pleno centro de la ciudad, fue tomada por un comando universitario radical. Desde allí se lanzaron toda clase de arengas violentas. Esto dijo el funcionario Rafael Azula Barrera en calidad de testigo excepcional de los hechos: "Me comuniqué con la Radiodifusora Nacional, en poder de los amotinados. Se sentía una gritería ensordecedora de gentes ebrias. La voz de la persona que me contestaba, con palabras incoherentes, apenas se percibía entre los gritos" (Azula, 1956, p. 353).

A las tres horas de ocurridos los hechos, y tras escuchar directamente de la radio el desarrollo de los acontecimientos, el presidente Ospina Pérez pidió enviar patrullas del ejército para tomar a toda costa las emisoras particulares y la Radiodifusora Nacional en poder de los agitadores (Estrada, 1948). Pocos minutos después, la situación seguía igual, lo que indujo al Presidente a impartir instrucciones al ministro de guerra Fabio Lozano y Lozano y al ministro de correos y telégrafos José Vicente Dávila Tello para recuperar a toda costa esta estación, pues se consideraba que era clave por su importancia y poder de cubrimiento nacional. Simultáneamente, se pidió al gerente de la empresa de energía para que suspendiera el servicio de luz y así "se evite que se continúe incendiando al país por la radio", medida esta que no fue atendida debido al caos reinante.

La emisora Nueva Granada fue ocupada bajo la colaboración de uno de sus locutores, Eugenio Cañavera, y con el apoyo de periodistas de los diarios El Liberal, La Razón y El Tiempo. A las pocas horas, entraron en cadena con el colega Rómulo Guzmán del radioperiódico Últimas Noticias (Braun, 2008).

Solo hasta las horas de la noche, la estación fue recuperada por el gobierno gracias a la presión de las fuerzas del orden y a la acción de dos jóvenes conservadores de apellido Soriano y Zuluaga. A través de señales emitidas desde el palacio presidencial, las principales autoridades políticas y militares reprodujeron constantemente mensajes haciendo un llamado a la cordura y coordinando las acciones con miras a la reconstrucción y normalización de las actividades (Alape, 1983). Como era apenas lógico, la actitud asumida por los gobiernistas consistió en minimizar la verdadera magnitud de los trágicos acontecimientos, haciendo creer que las Fuerzas Armadas tenían completo dominio de 
la situación. Para ello, se hizo un vehemente llamado a rechazar informaciones lanzadas por otras emisoras.

Aparte de las estaciones tomadas a la fuerza, las voces rebeldes buscaron la forma de hacerse oír a través de la denominada Voz del Pueblo, una emisora clandestina que decía transmitir desde un "refugio secreto" y que aparentemente contaba con equipos portátiles de transmisión en todos los puntos cardinales de la ciudad. Al aire y en claves secretas se establecieron supuestos contactos con corresponsales ubicados en el sur y en Usaquén, al norte de la ciudad. Como estrategia de defensa, la emisora cambiaba continuamente de frecuencias para burlar a los posibles saboteadores (Canal, 1948).

Hubo otros más arriesgados, como Cristóbal Pérez, quien llevó los micrófonos y parlantes de Radio Cristal hasta la carrera $7^{\text {a }}$ para difundir de manera directa las proclamas revolucionarias lanzadas a lo largo de esta céntrica vía capitalina a fin de que los oyentes pudieran percibir el estruendo de la frenética multitud. Por esta incitación al desorden, a los dos días este hombre apareció asesinado en una población cercana a Bogotá (Téllez, 1974).

La radio se constituyó también en un espacio a través del cual se buscó mantener el control sobre otras alternativas de comunicación. Por varios testimonios se sabe que desde el radioperiódico Últimas Noticias, emitido a través de la emisora Voz de Bogotá, se leyó repetidas veces un comunicado de la Unión de Sindicatos de Comunicaciones de Colombia (UNDESCOM), en el que se hizo un llamado a todos sus afiliados, empleados y exempleados del Ministerio de Correos y Telégrafos, para que se pusieran a órdenes del Comité Ejecutivo de la Revolución, desconocieran el gobierno conservador y se apoderaran de las oficinas de comunicaciones, poniéndolas al servicio del movimiento insurreccional (Sánchez, 1983).

El mismo día de los hechos, uno de los representantes de la Junta Revolucionaria de Gobierno pronunció las siguientes palabras por los micrófonos de la emisora Nueva Granada haciendo creer que el movimiento revolucionario mantenía el control absoluto de las comunicaciones:

Todo el país es hoy revolucionario. Los teléfonos nos pertenecen. El mismo gerente doctor Luis Carlos Álvarez organiza los teléfonos para nosotros. El telégrafo y los correos son nuestros. La Marconi está en manos del pueblo y nos estamos comunicando con todos los departamentos de donde tenemos noticias confirmadas de nuestro triunfo (Canal, 1948, p. 15).

Enseguida, se dictaron órdenes a copartidarios con nombres propios para que en cada una de sus provincias se encargaran de la dirección de las comunicaciones en sus dependencias de telégrafos y radiogramas.

\section{La diáspora de la "chispa" radial a escala regional}

Las primeras informaciones sobre el asesinato del líder político liberal llegaron a las provincias por cuenta de las señales emitidas por las emisoras de la ciudad de Bogotá. Esto 
explica la simultaneidad que adquirió el movimiento de sublevación a nivel provincial y la uniformidad en las medidas adoptadas, lo cual hizo pensar a muchos sectores conservadores que ese había sido un plan concebido con antelación (Sánchez, 1982).

Un buen número de estaciones ubicadas en las principales ciudades del país fueron ocupadas abruptamente (ver tabla 1) y se convirtieron en caja de resonancia del sentimiento de descontento.

Tabla 1. Emisoras ocupadas a la fuerza durante los hechos del 9 de abril de 1948

\begin{tabular}{|l|l|}
\hline Ciudad & Emisoras \\
\hline Bogotá & $\begin{array}{l}\text { Nueva Granada, Radio Cristal, La Voz de Colombia, La Voz de Bogotá, Radio } \\
\text { Panamericana, Ondas Bogotanas }\end{array}$ \\
\hline Medellín & La Voz de Antioquia, Emisora Cultural de la Universidad de Antioquia \\
\hline Cali & Radio Pacífico, La Voz del Valle \\
\hline Buga & Guadalajara \\
\hline Cartago & La Voz del Palatino \\
\hline Pasto & Ecos de Pasto \\
\hline Manizales & Radio Manizales \\
\hline Barranquilla & Emisoras Unidas \\
\hline Honda & Ecos del Gualí \\
\hline Ibagué & Ecos del Combeima \\
\hline Bucaramanga & Radio Santander \\
\hline
\end{tabular}

Fuente: Alape (1989) y Sánchez (1982).

Una de las localidades en donde se sintió con más ímpetu la noticia fue en el municipio de Barrancabermeja, puerto ribereño sobre el río Magdalena. Allí se registró una rápida respuesta a los llamados provenientes de la capital, lo cual dio lugar a la conformación de una junta revolucionaria que gobernó la ciudad por varios días y que puso en vilo al país por la amenaza que se cernía sobre este que era el más grande enclave petrolero (Díaz, 1989).

En Medellín, un grupo enardecido de liberales y comunistas se tomaron la Voz de Antioquia y la Emisora Cultural de la Universidad de Antioquia y pronunciaron desde allí sendos mensajes incendiarios. Luego, estas estaciones fueron tomadas a la fuerza por los organismos policivos (Alape, 1989) y todas las emisoras de esta capital transmitieron en cadena una alocución del recién posesionado gobernador conservador Dionisio Arango Ferrer en la que se recalcaba la adhesión irrestricta al gobierno nacional, censurando de paso la conducta de los amotinados. No obstante, desde Bogotá se siguió alentando al pueblo y a los obreros antioqueños a mantenerse firmes en la lucha y a desconocer las noticias falsas emitidas por los oficialistas. 
En la ciudad de Cali La Voz del Valle sufrió serios destrozos. En el municipio de Trujillo, el atemorizado alcalde optó por suspender el servicio de energía eléctrica con el fin de que los radios no pudieran funcionar pues para esta época todavía no se conocía el transistor ${ }^{8}$. En la ciudad de Buga, la emisora Guadalajara fue puesta bajo control de las brigadas revolucionarias (Sánchez, 1982). En Cartago los amotinados se tomaron La Voz del Palatino y desde allí lanzaron arengas para el norte del Valle (Betancourt, 1987).

En la ciudad de Pasto se presentó un caso excepcional, pues allí las directivas de Ecos de Pasto, previendo la conmoción que sobrevendría, tomaron la precaución de sacar la emisora del aire. Con esta acción, se salvaron de que este establecimiento fuera incendiado pues esa era la intención del alcalde y de la policía de clara orientación conservadora (Rosero, 1996).

El puerto de Barranquilla tampoco fue ajeno a los tumultos. Desde estaciones bogotanas se escuchó el llamado a los líderes de la protesta a deponer sus armas para ser reemplazadas por una junta revolucionaria mientras que la radio local, Emisoras Unidas, incitaba al pueblo al desorden (Blanco, 1968).

Aparte de los saqueos y de la abusiva utilización de los equipos de radio, en algunos casos la violencia provocó graves consecuencias como el incendio que acabó con la Voz de Colombia de orientación conservadora y Radio Pacífico que fue dinamitada.

En la ciudad de Manizales, tan pronto se supo la noticia, una multitud rodeó las instalaciones de Radio Manizales (Sánchez, 1982). En Ibagué, los dirigentes liberales Felipe Salvador, Héctor Echeverri Cárdenas, Simón de la Pava e Ismael Santofimio se dirigieron hasta las dos emisoras que existían en la ciudad y allí se turnaron para lanzar arengas incendiarias a la multitud. Asimismo, se usaron las ondas de radio para impartir órdenes y consignas a los liberales de las demás poblaciones del Tolima (Jaramillo, 1983). Al norte de este departamento, en el municipio del Líbano, se conformó una junta revolucionaria que expidió un decreto mediante el cual se les notificó a los conservadores confinados que les quedaba absolutamente prohibido escuchar radio (Sánchez, 1982).

En Bucaramanga, los liberales encabezados por Hernando Caballero, irrumpieron en las instalaciones de Radio Santander armados de cuchillos, palos, hachas y machetes, desplazando a los pocos empleados que estaban al frente de las transmisiones habituales. Una vez apaciguados los ánimos, varios personajes liberales de gran influencia en la actividad política regional se tomaron los micrófonos para exigir calma al pueblo enardecido. Para este propósito, el grupo de políticos pidió al dueño de la emisora la instalación de un alto parlante en la ventana de una de las casas céntricas de la ciudad para persuadir a la multitud a fin de que se dispersaran, moderaran el consumo de bebidas embriagantes y evitaran atentar contra las edificaciones (Hernández, 1998).

Aparato inalámbrico que recibe ondas de radio y las transforma en sonido. 


\section{Medidas de control}

La censura en torno a la radio, tras los sucesos del 9 de abril de 1948, estuvo predeterminada por un conjunto de variables dentro de las cuales la más crucial fue la filiación política de los dueños de las emisoras, de los gobernantes locales y del sentir mayoritario de la ciudadanía9. Esto creó un complejo juego de poderes y álgidas confrontaciones.

A partir del asesinato de Gaitán, los gobiernos conservadores de Mariano Ospina Pérez, Laureano Gómez y Roberto Urdaneta Arbeláez emprendieron una rigurosa censura sobre la prensa hablada y escrita, un control político ejercido oficialmente a través de un paquete de medidas.

A nivel internacional, esta censura estaba enmarcada en el ambiente de la denominada Guerra Fría que pretendía contener la expansión de las ideas comunistas, que en ese momento eran consideradas como una amenaza para los sistemas democráticos del mundo occidental.

Ya algunas normas anteriores al Bogotazo habían fijado controles a las emisoras. El Decreto 1966 del 6 de julio de 1946 hizo énfasis en la moderación que debía caracterizar las transmisiones radiales con tal de que no alteraran el orden público y, en caso de guerra o de alguna perturbación al orden social, el Estado estaba facultado para suspender los servicios de transmisión (Chaves, 2014).

Los incidentes vividos el 9 de abril de 1948 impulsaron al gobierno del presidente Mariano Ospina Pérez a intervenir de una manera más decisiva las estaciones de radio. Nueve días después, se dictó el Decreto 1271 en el que, amparado bajo el estado de sitio, quedó con plena facultad de censurar la prensa y las telecomunicaciones mientras duraba el estado de emergencia, de manera que los pocos programas de información permitidos debían someterse a una censura previa antes de ser emitidos.

Asimismo, el gobierno se amparó en el mencionado Decreto 1966 para expedir el Decreto 1312 del 22 de abril de 1948, en el que ordenó que, a partir de la fecha, las estaciones de radiodifusión comercial, cultural y experimental no podían funcionar sino con permiso expreso del Ministerio de Correos y Telégrafos, y sus programas estarían sujetos a la autorización y revisión previa de este organismo estatal. Cualquier contravención a este mandato, acarrearía la pérdida definitiva de la licencia a la estación responsable. Aquellas emisoras que en virtud de este decreto prestaran servicio, de todas formas lo harían con carácter provisional y ateniéndose a las investigaciones y sanciones correspondientes.

Días más tarde, el 31 de mayo, a través del Decreto 1821 se informó que solo serían renovadas las licencias a quienes no hubiesen atentado contra el orden público ni contra las instituciones democráticas. Hábilmente, como una fórmula para estrechar el control, el gobierno nacional dispuso la creación de la Asociación Nacional de Radiodifusión (Anradio) y exigió a todas las emisoras tramitar la respectiva afiliación para lo cual debía

La polarización política entre liberales y conservadores adquirió marcados matices a escala provincial. Sobre este asunto, véase Latorre (2009). 
cumplirse con el requisito previo de contar con la licencia expedida por el Ministerio. En ese mismo decreto, el gobierno quedaba en libertad de imponer censura previa total en caso de perturbación del orden público (Archivo Central del Ministerio de Comunicaciones, 1948). Desde luego, las primeras en ingresar a la Asociación fueron las emisoras adeptas a las ideas del régimen conservador: la Voz de Antioquia, la Voz de Cúcuta, la Voz del Valle, la Voz de Pereira, Radio Bucaramanga, Radio Continental, Radio Manizales, Emisora Panamericana, Emisora Fuentes y Emisoras Unidas (Pareja, 1984).

Para neutralizar la intemperancia verbal, el Decreto 1787 del 31 de mayo de 1948 estableció que las conferencias de cualquier índole solo podían ser transmitidas previa autorización del Ministerio de Correos y Telégrafos, debiendo enviar la emisora a esta entidad una grabación de dicha alocución. Los noticieros solo podían ser transmitidos por estaciones de onda larga ${ }^{10} \mathrm{y}$ les era prohibido emplear un tiempo mayor de 60 minutos en un día, distribuidos en períodos máximos de 30 minutos. El concesionario de la licencia debía dar aviso previo al Ministerio indicando la hora exacta de la transmisión, el nombre de los locutores y las condiciones especiales del noticiero (Ministerio de Correos y Telégrafos, 1949).

El propósito de restringir estas transmisiones por onda larga era evitar que la exacerbación de cualquier locutor abarcara todo el territorio nacional. Se quiso con esta medida acabar con los antiguos radioperiódicos que, de manera casi indefinida, lanzaban al aire toda suerte de noticias apasionadas que poco a poco azuzaban los ánimos, tal como sucedió el 9 de abril de 1948.

El balance de estas medidas a julio de 1949 era, a juicio del ministro Dávila, altamente satisfactorio, exaltándose el acatamiento general a excepción de unos cuantos casos reprochables que ocurrieron sin la anuencia de los propietarios de las estaciones y que además de todo fueron rápidamente neutralizados.

De todos modos, el debate sobre los alcances de la radio seguía candente. El 26 de mayo de 1949 un periodista del diario capitalino El Tiempo aconsejó al gobierno proscribir toda propaganda política por radio en la medida en que había resultado imposible la moderación y veracidad de este tipo de transmisiones (Ministerio de Correos y Telégrafos, 1949).

Las medidas restrictivas de carácter oficial se extendieron también a los radiaficionados. Teniendo como premisa que las telecomunicaciones eran la base primordial de la defensa nacional y, en aras de la conservación del orden público, el presidente Ospina Pérez y su ministro de correos y telégrafos José Vicente Dávila Tello, optaron por cancelar a partir del 19 de mayo de 1948 todas las licencias de radioaficionados, locutores y radiotécnicos, a quienes se les concedió un plazo de treinta días para solicitar un nuevo permiso. En el

10 Dentro de la escala técnica de clasificación de emisoras, las de onda larga eran las comprendidas entre 530 y 1600 kilociclos. Las de banda tropical tenían una frecuencia aproximada a los 4 y 6 megaciclos. Las de onda corta o banda internacional se ubicaban entre los 6 y 21 megaciclos. Los canales preferenciales estaban comprendidos entre 530 y 980 kilociclos con un mínimo de 10 kilovatios de potencia mientras que las regionales funcionaban en frecuencia de 1000 a 1200 kilociclos (Ministerio de Correos y Telégrafos, 1949). 
caso específico de los radioaficionados y radiotécnicos, tan solo se otorgaron permisos a quienes figuraban como reservistas certificados por el Ministerio de Guerra.

Para asegurar el cumplimiento de este requisito, el Ministerio de Guerra dictó el Decreto 2170 del 28 de junio de 1948 mediante el cual se estableció que, en caso de guerra exterior o conmoción interna, aquellos reservistas con licencia de radiaficionados debían presentarse inmediatamente a la autoridad militar más próxima, tan pronto fuera declarado el estado de sitio (Ministerio de Correos y Telégrafos, 1948). Edmundo Quiñónez y Gabriel Galo Dugand, ambos reservistas del Ejército Nacional de la 1. ${ }^{\text {c clase de }}$ radiocomunicaciones, figuraron entre los primeros en obtener licencia (así lo consagra el Decreto 2170 de 1948)

En desarrollo de las normas posteriores al 9 de abril, el Ministerio de Guerra había otorgado a 31 de mayo de 1949 un total de 96 licencias para radioaficionados y 56 para radiotécnicos, y además se entregaron licencias de locutores a 366 personas (Ministerio de Correos y Telégrafos, 1949).

\section{Censuras en Bogotá y en las regiones}

Quizás la estrategia de censura más aplicada por el gobierno nacional, a través del Ministerio de Correos y Telégrafos, fue la cancelación de las licencias de emisoras comprometidas en la revuelta del Bogotazo y sindicadas de emitir programas "subversivos". Para ello, se apoyó en lo dispuesto por el artículo 10 del Decreto 1966 de 1946.

En Bogotá, a la emisora Nueva Granada se le dictó el 12 de mayo de 1948 orden para suspender actividades tras adelantarse una investigación sobre su responsabilidad en los episodios del 9 de abril "consistente en la transmisión por sus micrófonos de incitaciones al desconocimiento de las autoridades legítimas y a la perturbación del orden público". Esa misma sanción le fue aplicada a Radio Cristal HJCU, HJCA y Emisora Panamericana HJCY (véase en este caso el Decreto 1966 de 1946) reglamentario de los servicios de radiocomunicaciones). Según palabras del propio ministro del ramo, estas estaciones habían incurrido en transmisiones de carácter "revolucionario y sedicioso". (R, Pita. Comunicación personal. 16 de agosto 2016.)

Ese mismo día, mediante Resolución ejecutiva 53, se declaró la caducidad de los contratos firmados en 1913 para el funcionamiento de las emisoras La Voz de Bogotá HJCC, HJCF y Ondas Bogotanas HJCE, por transmitir noticias falsas y tendenciosas y por incitar a la violencia. Asimismo, se les culpó por no conservar el texto escrito de las transmisiones. Sin embargo, el director de Ondas Bogotanas alegó que, si bien por sus micrófonos se habían propagado esas proclamas incendiarias, las directivas y los empleados no eran responsables de ello puesto que la emisora había sido tomada a la fuerza por los revoltosos (Sánchez, 1983).

En igual sentido, otras estaciones bogotanas se defendieron aduciendo que el asalto había sido sin su consentimiento. Así las cosas, muchas de las drásticas sanciones impues- 
tas en un principio fueron sustituidas por otras más moderadas como en el caso de las emisoras Nueva Granada y La Voz de Bogotá, a las cuales se les sancionó con la pérdida temporal de su nombre en la identificación de sus transmisiones. Otro ejemplo de ello fue Radio Panamericana que al cabo de un tiempo logró recuperar su licencia pero bajo el nuevo nombre de Radio Metropolitana. Uno de los pocos radiodifusores sometido a consejo de guerra fue Roberto Ramírez Gaviria (Téllez, 1974).

El 25 de agosto se canceló la licencia a la emisora comercial Sumapaz de la población de Fusagasugá, ubicada a pocas leguas de Bogotá, todo porque desde sus equipos "se emitieron arengas revolucionarias altamente atentatorias contra la seguridad del país, la seguridad de las personas y el respeto debido a las autoridades legítimas, de incitación a la revuelta y al desconocimiento de la ley" (Archivo Central del Ministerio de Comunicaciones, 1948, libro 17, f. 135).

Teniendo como precedente la abundante reglamentación dictada por el gobierno nacional al poco tiempo de ocurridos los hechos del 9 de abril, a nivel departamental y local, algunos mandatarios no dudaron en imponer sus propias medidas.

En Barranquilla las turbas incontroladas se tomaron la sede de la gobernación y conformaron una junta revolucionaria. Al oírse en esta ciudad las incendiarias proclamas emitidas por Emisoras Unidas, el gobernador del departamento del Atlántico, José Martín Blanco Núñez y su secretario de gobierno, ambos de orientación gaitanista, decidieron llamar telefónicamente al Comando de la Policía Nacional para que hiciera callar la estación local. Rafael Roncallo, el dueño de la estación, logró comunicarse con el gobernador informándole que una gran multitud de amotinados había invadido sus estudios con amenazas de que sería incendiado este establecimiento. Roncallo clamó afanosamente la presencia de soldados y policías para no sucumbir a los dictámenes de la enfurecida turba.

El 10 de abril, Blanco Núñez dictó el toque de queda en la ciudad y expidió un decreto en el que dispuso en su artículo $1^{\circ}$ que todas las radiodifusoras del Departamento estarían bajo inspección directa del gobierno seccional y solo podían emitir noticias suministradas por la gobernación, reservándose esta entidad la facultad de ocupar las instalaciones que considerara necesario para la transmisión de noticias y boletines oficiales. Los infractores serían sancionados con multas de 500 pesos la primera vez y con el cierre de la estación en caso de reincidencia (Secretaría de Gobierno del Atlántico, 1948).

En desarrollo de este último punto y con el fin de contrarrestar el efecto desorientador de algunas emisoras que seguían atizando los ánimos políticos, se leyó al día siguiente por radio un boletín firmado por Blanco Núñez y por el coronel Carlos Perdomo Puyo, comandante de la $2^{a}$ Brigada del Ejército, en el que se hacía un llamado a restarle crédito a cualquier noticia "antipatriótica" y subversiva que contradijera las informaciones oficiales. Se hizo énfasis en restablecer la tranquilidad social gracias a la lealtad de las Fuerzas Armadas y a la cooperación que había mostrado el sector moderado del partido liberal con el gobierno legítimamente constituido (Secretaría de Gobierno del Atlántico, 1948). 
Dos días después, siguiendo el ejemplo de concordia nacional propuesto por el presidente Ospina Pérez, el gobernador Blanco Núñez creó una comisión con máximos dirigentes de los dos partidos para que, por medio de la radio, trataran de calmar los pueblos levantiscos del Departamento, todo con el fin de evitar la intervención directa de las fuerzas del orden, vía extrema que podía generar un espiral de violencia (Blanco, 1968).

Por los lados del sur de la República, el 27 de septiembre se señaló a la Voz del Trópico del municipio de Palmira en el departamento del Valle por haber dado a conocer las noticias sediciosas que se estaban emitiendo por las estaciones de radiodifusión de Bogotá y además porque sus micrófonos fueron usados por particulares y aun por el mismo concesionario de la licencia para pronunciar proclamas que estimulaban al desconocimiento del gobierno, la perturbación de la tranquilidad ciudadana y el irrespeto a las instituciones, procederes estos que reñían abiertamente con los reglamentos vigentes sobre radiodifusión (Archivo Central del Ministerio de Comunicaciones, 1948, libro 20, f. 39).

En su informe al Congreso Nacional, presentado en septiembre de 1948, el ministro Dávila Tello reconoció que las medidas adoptadas merecieron al principio una avalancha de críticas, pero, a medida que transcurrieron los días, fueron ganando asentimiento unánime. Este funcionario lamentó el hecho de que, cuando su cartera pretendía hacer cumplir la ley, era acusado por sus detractores como censura alegando móviles políticos. Defendía la intervención estatal como imparcial y, para probar esto, recordaba cómo los correctivos y sanciones habían cobijado a estaciones dirigidas por militantes de distintos partidos, incluso a los adictos al partido conservador que en ese momento estaba al frente del poder.

Dávila Tello reconoció que había hecho su mejor esfuerzo para subsanar las irresponsabilidades del sistema de telecomunicaciones y hacer valer no solo los pactos internacionales sino también las disposiciones estipuladas en el ámbito interno. Así entonces, se puso de presente cómo la Convención de la Unión Internacional de Telecomunicaciones, reunida hacía pocos meses en Madrid, en su artículo 37 había impuesto a los gobiernos afiliados el compromiso de adoptar las medidas idóneas para reprimir la transmisión de señales falsas o tendenciosas. Adicionalmente, se recordó que el Convenio Internacional de Telecomunicaciones reunido el 2 de octubre de 1947 en Atlantic City, había acogido la iniciativa colombiana contemplada en el artículo 8 de la Ley 198 de 1936 en la que se instaba a las estaciones de radiodifusión a no atentar contra la moral o la seguridad del país (Ministerio de Correos y Telégrafos, 1948).

Según Dávila Tello, la situación era tan irregular que algunas estaciones funcionaban en cabarets o sitios de diversión pública mientras que otras padecían de defectos técnicos que producían constantes interferencias.

El ministro subrayó el hecho de que no existía país en el mundo en donde la radiodifusión no estuviere bajo vigilancia del Estado e incluso se reconoció a Colombia como una de las naciones con más laxa legislación. Por lo anterior, creía este funcionario que 
era imperioso implantar unos controles más incisivos e inmediatos sobre estos medios que sobre otros, como el impreso:

Lo que ocurre es que la noticia o comentarios radiados impresionan directamente al oído de toda clase de personas, no invitan al raciocinio, sino que su rápido efecto sobre las pasiones de los hombres provoca con la mayor facilidad el desbordamiento de los bajos instintos de las gentes. No pasa lo mismo con la prensa escrita, que cuenta con un público más seleccionado, que su misma lectura incita al raciocinio, y es por eso por lo que nunca la prensa escrita produce las reacciones rápidas e incontroladas de la prensa hablada (Ministerio de Correos y Telégrafos, 1948, p. 10).

Lo cierto era que la experiencia vivida a raíz del Bogotazo sirvió además para que adquiriera nuevamente vigencia el debate sobre el tipo de instancia u organismo que debía regir la radiodifusión en Colombia. Para algunos, lo más conveniente era crear un consejo de radiodifusión. A manera de reflexión, se puso como ejemplo comparativo el caso de México en donde el control lo ejercía la Secretaría de Comunicaciones y Obras Públicas con personal nombrado por el gobierno. En Estados Unidos, entre tanto, existía la denominada Comisión Federal de Comunicaciones, compuesta por nueve miembros designados directamente por el Presidente de la República y dirigidos por el Secretario de Comunicaciones (Ministerio de Correos y Telégrafos, 1948).

Al tiempo que transcurrían estas discusiones, la sección técnica del Ministerio de Correos y Telégrafos se dedicó a incrementar su función de inspección de las telecomunicaciones, pese a las restricciones presupuestales. Para equiparse mejor adquirió un equipo de grabación que pertenecía anteriormente a la Empresa Nacional de Radiocomunicaciones y se gestionó la compra de nueve instrumentos de control a la compañía General Radio de Estados Unidos, incluyendo un medidor de intensidad de campo para señales de radio-frecuencia (Ministerio de Correos y Telégrafos, 1948).

Aun cuando el Estado de sitio había sido levantado el 17 de diciembre de 1948, todavía al año siguiente prevalecía en el país una atmósfera de tensión política. Varios acontecimientos de gran resonancia ocurrieron en el primer semestre de 1949: la celebración del día del trabajo, las elecciones de cuerpos colegiados y el aniversario del asesinato de Gaitán, hecho este que podía ser aprovechado por los partidos políticos para exacerbar de nuevo los ánimos.

Ante esto, el presidente Ospina Pérez y su ministro de gobierno, el coronel Régulo Gaitán dictaron el Decreto 1486 del 23 de mayo mediante el cual proscribieron las concentraciones políticas o sindicales, así como también las conferencias radiales de carácter político desde el 23 de mayo hasta el 7 de junio. Quedó vedado el consumo de bebidas embriagantes y el porte de armas, y se encargó a la Policía Nacional y a los gobernadores de cada departamento para que implementaran las acciones necesarias para el estricto acatamiento de estas normas.

Para poder llevar a cabo una manifestación pública, debía tramitarse con tres días de antelación el respectivo permiso ante el gobernador, prohibiéndose las reuniones 
multitudinarias simultáneas el mismo día. Las manifestaciones autorizadas no podían celebrarse sino en las vías y lugares previamente estipulados, con un motivo claramente definido y especificándose de antemano los nombres de los oradores escogidos y la duración de los actos.

Igualmente, se prohibió el uso de amplificadores de sonido instalados para información y propaganda política en lugares públicos y privados o en vehículos acondicionados como reproductores de programas emitidos por emisoras radiales (Ministerio de Gobierno, 1949).

En este mismo año, el Ministerio de Correos y Telégrafos (1949) publicó un folleto que contenía el estatuto legal que en Colombia regía para la radiodifusión, en el que se incluyeron todas las disposiciones vigentes, esto con el fin de mantener bien informado al sector y a la comunidad sobre el nuevo panorama de la radio.

Los dispositivos de control no cesaron con el paso de los años y fue así como en 1950 el gobierno incautó una radiodifusora en la ciudad de Bogotá y que actuaba con dos frecuencias bajo los nombres de Resistencia Liberal y Voces de Libertad (Acuña, 2013).

\section{Conclusiones}

Esta recapitulación histórica ha permitido comprobar los alcances de la radio, que para mediados del siglo XX había logrado penetrar la vida social y cotidiana de los colombianos, tanto en el área urbana como en el área rural. Un país con grandes dificultades de comunicación por su agreste geografía, un país de marcadas regiones en el que las ondas radiales lograban llegar más rápido que los limitados tirajes de la prensa en una sociedad que todavía tenía muchos retos en materia de alfabetismo y formación educativa.

Esos alcances de la radio pudieron percibirse en coyunturas especiales de violencia. Inmerso en un acentuado proceso de politización, este medio de comunicación sirvió no solo como espacio habitual de información, sino que también funcionó como canal para incitar, organizar, denunciar, confundir, aplacar y persuadir, según cada circunstancia específica.

El alto nivel de confrontación y polarización entre el partido Liberal y el partido Conservador se vio también reflejado en los medios de comunicación, siendo de esta forma muy difícil manejar la imparcialidad y la ecuanimidad. Esta conjunción de circunstancias contribuyó a propiciar los hechos violentos acaecidos el 9 de abril de 1948 en la ciudad de Bogotá y en gran parte del país en el que el nivel de intolerancia llegó a su máxima expresión con consecuencias funestas para las instalaciones, equipos y hombres de radio.

Estos desafueros y excesos sucedidos durante el Bogotazo desencadenaron una serie de cambios que configuraron el nuevo panorama de la radio en la segunda mitad del siglo XX. Particularmente, el control sobre las licencias de funcionamiento abrió paso para el surgimiento de monopolios en detrimento de las pequeñas iniciativas radiales. 
Asimismo, las censuras establecidas por la ley generaron una disminución ostensible de los espacios dedicados al debate político, al análisis y a la denuncia, ante lo cual se registró un auge de los programas de entretenimiento (Chaves, 2014). Con las censuras impuestas, la radio en Colombia perdió uno de sus propósitos principales que era el de ofrecer distintos puntos de vista frente a la realidad nacional con libertad de opinión pues por estos años primó la postura oficial del gobierno.

Con la llegada del régimen militar del general Gustavo Rojas Pinilla se adoptaron nuevas medidas de censura. Así, por ejemplo, en el mes de agosto de 1953 se promulgó el Decreto 2012 mediante el cual se reorganizó la Radiodifusora Nacional que desde ese momento quedó bajo inspección de la Oficina de Información y Propaganda. A los pocos días se reglamentó la solicitud de licencias de radiodifusión. El propósito de Rojas Pinilla fue utilizar la radio como un instrumento para divulgar las ideas y gestiones de su gobierno en los sectores populares de la población (Acuña, 2013).

Aun con todos estos controles, vale aclarar que en Colombia la censura nunca alcanzó la dimensión de las restricciones aplicadas en las dictaduras militares que proliferaron en América Latina en las décadas del 60 y 70.

En los años siguientes al Bogotazo, la radio vivió un proceso de expansión y modernización. Vertiginoso fue el incremento de receptores durante esta época pues mientras en 1952 existían 500000 de estos aparatos, a razón de 139 por cada 1000 habitantes, al cabo de siete años se registraban ya 2084287 (Reynolds y Pita, 2009). Era esta sin duda una prueba fehaciente del nivel de penetración de este medio de comunicación en la vida cotidiana de los colombianos.

A través de los micrófonos, en los años siguientes se difundirín los avatares de las reiteradas oleadas de violencia que azotaron al país: la época de la violencia" ${ }^{11}$ la guerra contra los grupos guerrilleros y desde la década del 80 la lucha contra el narcotráfico, los grupos paramilitares y las bandas criminales ${ }^{12}$.

Si bien algunos de estos actores políticos y armados han atentado contra los medios de comunicación a través de amenazas, presiones, agresiones y ataques terroristas, la situación dista mucho de lo ocurrido a mediados del siglo XX pues en ningún caso esos actores han logrado una influencia tan marcada sobre las emisoras o sobre las masas más allá del espectro local o regional. Una democracia más fortalecida, una sociedad con mayores estándares de educación y una radio fortalecida institucional y profesionalmente han sabido sortear esta serie de dificultades políticas que ha traído esta incesante historia de violencia.

Así entonces, en estos tiempos recientes no volvió a registrarse ningún hecho político que llegara a causar la magnitud del colapso social provocado aquella aciaga tarde del 9 de abril de 1948.

\footnotetext{
" Particularmente en esta etapa de cruda violencia ocurrida entre 1948 y 1957, sería el púlpito el que reemplazaría a la radio como amplificador de la consigna política (Alape, 1989).

12 Sobre esta relación entre violencia y medios en tiempos más recientes, véanse: Rey, 2007; Bonilla y Tamayo, 2006.
} 


\section{Referencias}

Acevedo Carmona, D. (2003). Prensa y confrontación política en Colombia, 1930-1950. En M. Segura (Ed.), VII Cátedra anual de historia Ernesto Restrepo Tirado. Medios y nación. Historia de los medios de comunicación en Colombia (pp. 283-309). Bogotá: Ministerio de Cultura,

Acuña Rodríguez, O. Y. (2013). Censura de prensa en Colombia, 1949-1957. Historia Caribe, 8(23), 241-267.

Alape, A. (1983). El Bogotazo. Memorias del olvido. Bogotá: Lerner.

Alape, A. (1989). El 9 de abril en provincia. En Planeta (Eds.), Nueva historia de Colombia (tomo II) (pp. 57-81). Bogotá: Editorial Planeta.

Albert, P. y A. J. Tudesq. (2002). Historia de la radio y la televisión. Ciudad de México: Fondo de Cultura Económica.

Amaya Trujillo, J. (2010). Historia y comunicación social: apuntes para un diálogo inconcluso. Aproximación crítica al campo de estudios históricos en comunicación. Comunicación y Sociedad, 13, 149-171.

Archivo Central del Ministerio de Comunicaciones (ACMC). (1948). Fondos: decretos, resoluciones. Bogotá: El Ministerio.

Atehortúa Cruz, A. L. (2009). El cuartelazo de Pasto. Historia Crítica, 37, 148-169. Recuperado de http://www.scielo.org.co/scielo.php?script=sci_arttextEpid $=$ S0121 16172009000100010

Azula Barrera, R. (1956). De la revolución al orden nuevo. Proceso y drama de un pueblo. Bogotá: Kelly.

Betancourt Echeverry, D. (1987). El 9 de abril en Cali y en el Valle. Acciones de la muchedumbre. Anuario de Historia Social y de la Cultura, 15, 273-285. Recuperado de https://revistas.unal.edu.co/index.php/achsc/article/view/36113/37541

Blanco Núñez, J. M. (1968). Memorias de un gobernador. El nueve de abril de 1948 antes, durante y después. Barranquilla: Dovel.

Bonilla Vélez, J. I. y Tamayo Gómez, C. A. (2006). Medios de comunicación y violencia en América Latina: preocupaciones, rutas y sentidos. Controversia, (187), 111 171.

Braun, H. (2008). Mataron a Gaitán. Vida pública y violencia urbana en Colombia. Bogotá: Aguilar.

Cadena D’Costa, A. (1940). Memorias a las Honorables Cámaras. Bogotá: Imprenta Nacional.

Canal Ramírez, G. (1948). Nueve de abril de 1948. Bogotá: ABC.

Castellanos Prieto, N. (2001). La radio colombiana: una historia de amor y de olvido. Revista Signo y Pensamiento, 20(39), 15-23. Recuperado de http://revistas.javeriana.edu.co/index.php/ signoypensamiento/article/view/2939 
Cárdenas Ruíz, J. D. (2012). Una aproximación a la cultura política colombiana desde el debate contemporáneo de la democracia. Revista Facultad de Derecho y Ciencias Políticas, 42 (117), 393-424.

Chaves Castro, M. P. (2014). Transformaciones de la radio en Colombia. Decretos y leyes sobre la programación y su influencia en la construcción de una cultura de masas. (Monografía, Pontificia Universidad Javeriana). Recuperado de https://repository.javeriana.edu.co/bitstream/ handle/10554/12166/ChavesCastroMariadelPilar2014.pdf?sequence $=1$ EisAllowed $=y$

Checa Godoy, A. (2008). Historia de la comunicación: de la crónica a la disciplina científica. La Coruña: Netbiblo.

Díaz Callejas, A. (1989). El 9 de abril de 1948 en Barrancabermeja. Diez días de poder popular. Bogotá: Fescol.

Estrada Monsalve, J. (1948). El 9 de abril en Palacio. Horario de un golpe de Estado. Bogotá: Cahur. Galindo Hoyos, J. R. (2008). Gaitán el orador. Bogotá: Universidad Libre.

Gómez Mompart, J. L. (2015). Historiar la comunicación: conceptos y práctica investigadora. Revista Brasileira de História da Mídia, 4(1), 11-20.

Gutiérrez, E. (2009). Radio: identidad, mercado y trama profunda de la vida cotidiana: anotaciones de historias de la radio en Colombia 1928 2000. En Ministerio de Tecnologías de la Información y las Comunicaciones (Ed.), Trayectoria de las comunicaciones en Colombia (pp. 681-717). Bogotá: El Ministerio.

Guzmán, G., Fals Borda, O y Umaña, E. (2005). La violencia en Colombia (2 tomos). Madrid: Taurus.

Hernández Velasco, H. E. (1998). El 9 de abril de 1948 en Santander. Bucaramanga: Universidad Industrial de Santander.

Jaramillo, C. E. (1983). Ibagué: conflictos políticos de 1930 al 9 de abril. Bogotá: Centro Cultural Jorge Eliécer Gaitán.

Lalinde, A. M. (1998). Radio informativa y participación ciudadana. En J. Martín-Barbero y F. López de la Roche (Eds.), Cultura, medios y sociedad (pp. 152 169). Bogotá: Universidad Nacional de Colombia.

Latorre Rueda, M. (2009). Elecciones y partidos políticos en Colombia. Bogotá: Universidad de Los Andes.

Martín-Barbero, J. (2003). De los medios a las mediaciones. Comunicación, cultura y hegemonía. Bogotá: Convenio Andrés Bello.

Ministerio de Correos y Telégrafos. (1948). Informe del Ministro al Congreso Nacional. Bogotá: Imprenta Nacional.

Ministerio de Correos y Telégrafos. (1949a). Franquicias postal y telegráfica y otras disposiciones sobre Radiodifusión. Bogotá: Imprenta Nacional. 
Ministerio de Correos y Telégrafos. (1949b). Memoria de 1949. Bogotá: Imprenta Nacional.

Ministerio de Gobierno. (1949). Memoria del ministro de Gobierno al Congreso de 1949. Bogotá: Imprenta Nacional.

Pareja, R. (1984). Historia de la radio en Colombia, 1929-1980. Bogotá: Servicio Colombiano de Comunicación Social.

Pérez Ángel, G. (1998). La radio del tercer milenio. Caracol 50 años. Bogotá: Caracol.

Presidencia de la República. Decreto 1966 de 4 de julio de 1946, reglamentario de los servicios de radiocomunicaciones. Diario Oficial 26183, Bogotá.

Presidencia de la República. (1948). Decretos extraordinarios expedidos por la rama ejecutiva en desarrollo del artículo 121 de la Constitución Nacional. 1948. Bogotá: Imprenta Nacional.

Presidencia de la República. (1946). Decreto 1966 de julio 4 reglamentario de los servicios de radiocomunicaciones. Diario Oficial 26138 de julio 18 de 1946, Bogotá.

Presidencia de la República. (1948). Decreto 2170 de junio 28 por el cual se reglamenta la expedición de certificados de reservistas a los radioaficionados y radiotécnicos y se dictan otras medidas. Diario Oficial 26762 de julio 8 de 1948, Bogotá.

Rey, G. (2007). Las violencias en los medios, los medios en las violencias. Bogotá: Cinep.

Reynolds Pombo, J. y Pita Pico, R. (2009). Elementos para la historia de la radio en su desarrollo tecnológico, siglo XX. En Ministerio de Tecnologías de la Información y las Comunicaciones (Ed.), Trayectoria de las comunicaciones en Colombia (tomo II) (pp. 719-739). Bogotá: El Ministerio.

Rosero Arteaga, R. (1996). La historia de la radio en Nariño. Pasto: Imaginación.

Sánchez Gómez, G. (1983). Los días de la revolución. Gaitanismo y 9 de abril en provincia. Bogotá: Centro Jorge Eliécer Gaitán.

Sánchez, G. (1982). El gaitanismo y la insurrección del 9 de abril en provincia. Anuario de Historia Social y de la Cultura, (10), 191-229. Recuperado de http://www.revistas.unal.edu.co/ index.php/achsc/article/view/30258

Schudson, M. (1993). Enfoques históricos a los medios de comunicación. En K.B. Jensen y N.W. Jankowski (Eds.), Metodologías cualitativas de investigación en comunicación de masas (pp. 221 ) Barcelona: Bosch Comunicación.

Secretaría de Gobierno del Atlántico. (1948). Informe que rinde el señor Secretario de Gobierno al señor Gobernador del Departamento. Barranquilla: Imprenta Departamental.

Téllez, T. (1974). Cincuenta años de radiodifusión en Colombia. Medellin: Bedout.

Williams, R. (Coord.) (1992). Historia de la comunicación. Barcelona: Casa Editorial Bosch. 